\title{
ANÁLISE GEOESTATÍSTICA DA SALINIDADE DOS AQÜÍFEROS DA BACIA DE TAUBATÉ
}

\author{
ALEXANDRE CAMPANE VIDAL' $\&$ CHANG HUNG KIANG ${ }^{2}$
}

\begin{abstract}
GEOSTATISCAL ANALYSIS OF GROUNDWATER SALINITY OF TAUBATÉ BASIN This paper shows the results of salinity mapping of the Taubaté Basin groundwater, taking in consideration its structural compartments. The Taubaté Basin Groundwater is characterized by a strong hydrochemical variability, where the salinity ranges from $19 \mathrm{mg} / \mathrm{L}$ to $1.200 \mathrm{mg} / \mathrm{L}$. This variation is a direct consequence of structural compartments and lithologic distribution of the Taubaté Group. The aim of the present work is to define salinity distribution, considering the subbasins within the Taubaté Basin. The salinity map was produced by geostatistical analysis, grouping the results of each structural compartment. This procedure produced lower estimation errors when compared with the whole basin estimative.
\end{abstract}

Keywords: Taubaté Basin, geostatistics, hydrogeochemistry.

Resumo A Bacia de Taubaté apresenta grande heterogeneidade hidroquímica de seus aquíferos, com salinidade que varia de $19 \mathrm{mg} / \mathrm{L}$ a $1.200 \mathrm{mg} / \mathrm{L}$, consequêencia da compartimentação estrutural e da distribuição litológica do Grupo Taubaté. Este trabalho buscou a definição da distribuição da salinidade, considerando as sub-bacias que compõem a Bacia de Taubaté. O mapa de salinidade foi produzido com base na análise geoestatística de cada compartimento estrutural. Este procedimento produziu melhor estimativa da salinidade, se comparado com a análise de todos os dados em conjunto, demonstrando a importância do conhecimento geológico-estrutural em estudos hidrogeológicos.

Palavras-chave: Bacia de Taubaté, geoestatística, hidrogeoquímica.

INTRODUÇÃO Estendendo-se ao longo do Vale do Rio Paraíba do Sul, em aproximadamente $3.000 \mathrm{~km}^{2}$, a Bacia de Taubaté está posicionada no principal eixo de ligação entre os grandes centros urbanos de São Paulo e Rio de Janeiro (Fig. 1).

A alta densidade demográfica, aliada às boas características de fluxo das rochas-reservatório, com vazões de alguns poços superiores a $100 \mathrm{~m}^{3} / \mathrm{h}$, ocasionou a intensa exploração da água subterrânea. Nos municípios de São José dos Campos, Lorena e Capivari, a totalidade da água destinada ao abastecimento público é proveniente de poços semi-artesianos (Campos 1993).

No entanto, a exploração do aquífero não é uniforme ao longo de toda a bacia, em virtude da grande variação da capacidade de fluxo, influenciada diretamente pela heterogeneidade litológica (DAEE 1977, Teissedre \& Mariano 1978).

A variação litológica não apenas influencia as condições de fluxo, mas também a composição química da água subterrânea. Áreas com predomínio de sedimentos de origem fluvial apresentam águas com $\mathrm{pH}$ ácido-neutro e baixa salinidade, enquanto águas com pH neutro-alcalino e alta salinidade estão presentes onde predominam sedimentos lacustres.

Buscando a caracterização hidroquímica dos aquíferos da Bacia de Taubaté, Vidal \& Chang $(1998,2002)$ observaram a relação direta entre os tipos hidroquímicos e a salinidade da água subterrânea. Os autores enfatizaram que a compreensão da distribuição espacial da salinidade é de grande importância como indicador da composição química da água subterrânea e para avaliar, de forma indireta, a provável composição litológica em cada zonalidade hidroquímica.

Assim, buscou-se neste trabalho, através de métodos geoestatísticos, a determinação da variação da salinidade no Sistema Aqüífero Taubaté.

GEOLOGIA A Bacia de Taubaté faz parte de um conjunto de bacias pertencentes ao Rifte Continental do Sudeste do Brasil (Riccomini 1989) e está posicionada sobre o substrato précenozóico, representado por rochas ígneas e metamórficas, do Cinturão de Dobramentos Ribeira (Hasui \& Poçano 1978).

A estruturação alongada da bacia é condicionada por descontinuidades do embasamento pré-cambriano, de direção geral ENE, que favoreceram a tectônica ressurgente. A tectônica implantada foi do tipo rifte, com a formação de semi-grabens separados por zonas de transferência ou de acomodação, com depocentros invertidos e leques aluviais associados as falhas

As zonas de transferência, representadas pela Falha de São José e pelos altos de Caçapava e de Pindamonhangaba, subdividiram a bacia em quatro compartimentos (Fig. 2): o Compartimento Parateí, a oeste da Falha de São José; o Compartimento JacareíSão José dos Campos, inserido entre a Falha de São José e o Alto de Caçapava; o Compartimento Quiririm-Taubaté, posicionado entre os Altos de Caçapava e Pindamonhangaba; e, por fim, o Compartimento Aparecida-Lorena, presente a leste do Alto de Pindamonhangaba (Fernandes 1993).

O preenchimento da bacia pode ser dividido em duas fases: a primeira, sintectônica, com a deposição dos sedimentos do Grupo

\footnotetext{
1 - UNICAMP/IG/Departamento de Geologia e Recursos Naturais. R. Pandiá Calógeras, 51 CEP: 13083-970, Caixa Postal 6152, Campinas - SP. e-mail vidal@ige.unicamp.br

2 - UNESP/IGCE/Departamento de Geologia Aplicada, Av. 24-A, n¹515 CEP-13506-900 Rio Claro, SP. e-mail: chang@rc.unesp.br
} 


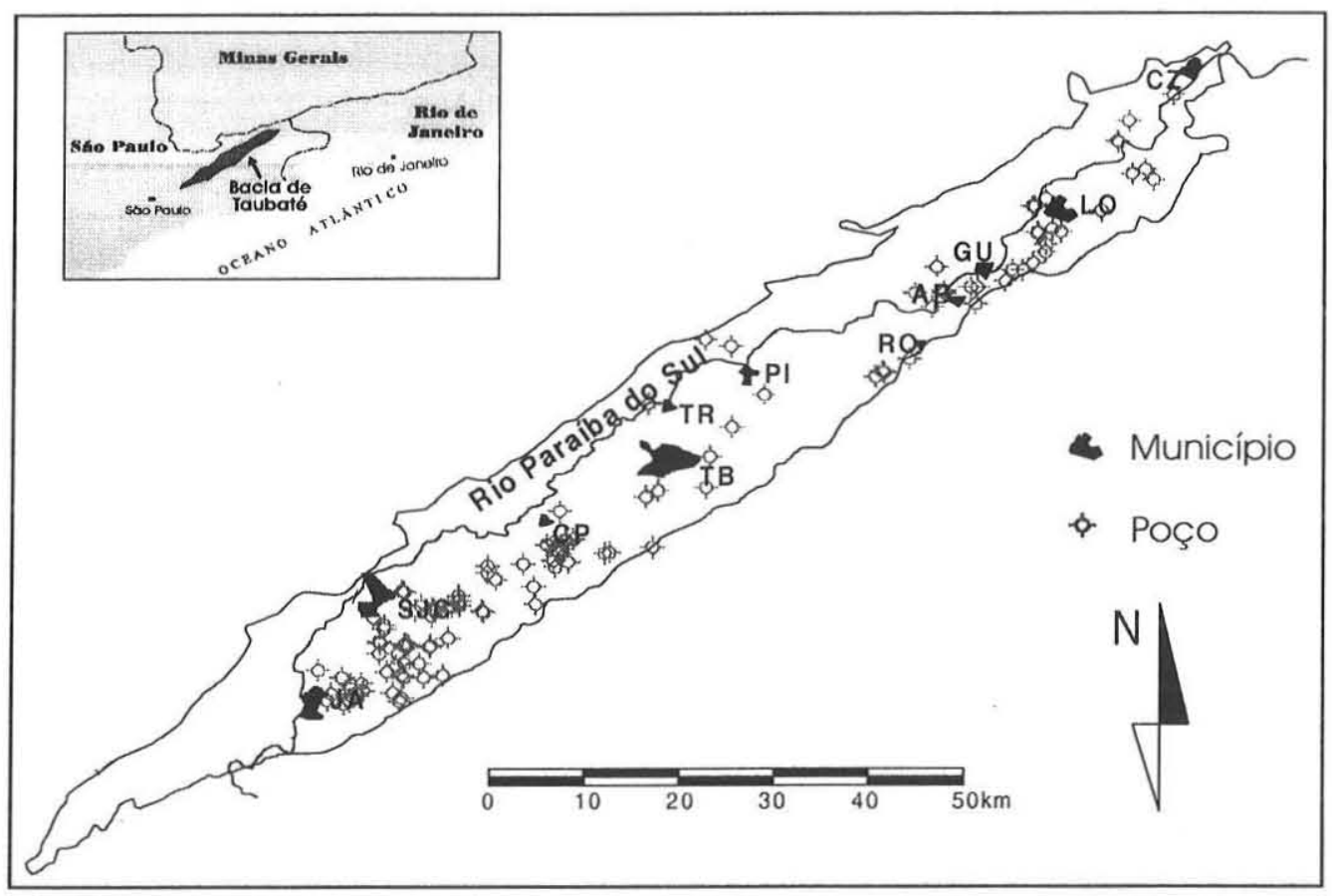

Figura I - Mapa de localização da área, com as principais cidades e os poços que tiveram suas águas amostradas. JA - Jacareí, SJC - São José dos Campos, CP - Caçapava, TB - Taubaté, TR - Tremembé, PI - Pindamonhangaba, RO - Roseira, AP - Aparecida do Norte, GU - Guaratinguetá, LO - Lorena, CZ - Cruzeiro.

Taubaté; e a segunda, posterior à tectônica diastrófica, com a deposição da Formação Pindamonhangaba e depósitos aluviais e coluviais quaternários (Riccomini 1989).

Depositado durante o Paleógeno, o Grupo Taubaté é subdividido nas formações Resende, Tremembé e São Paulo. A Formação Resende é constituída por um sistema de leques aluviais associados à sedimentação fluvial de rios entrelaçados. As fácies proximais são compostas por conglomerados polímiticos, interdigitados com arenitos e lamitos arenosos, oriundos de corridas de lama. Nas porções distais predominam os sedimentos formados em ambiente de planície aluvial, que correspondem a arenitos intercalados com lamitos.

A Formação Tremembé, formada por depósitos lacustres do tipo playa-lake, interdigita-se lateral e verticalmente com os sedimentos da Formação Resende, e constitui a unidade mais significativa da porção central da bacia. Segundo Riccomini (1989), a Formação Tremembé apresenta as fácies argilito verde maciço, dolomitos tabulares, ritmitos formados pela alternância de folhelhos e margas, arenitos com estratificação cruzada sigmoidal e granodecrescência de areia média até silte e arenitos grossos arcoseanos.

A Formação São Paulo compreende depósitos de um sistema fluvial meandrante, sendo as principais fácies compostas por arenitos grossos a conglomeráticos, com abundante estratificação cruzada; siltitos, argilitos laminados e arenitos médios e grossos gradando para sedimentos mais finos. Na Bacia de Taubaté, a ocorrência desta formação está restrita à porção sudoeste.

Sobreposto ao Grupo Taubaté, ocorrem os sedimentos da Formação Pindamonhangaba que, depositados no Neoterciário, correspondem aos depósitos de um sistema fluvial meandrante,

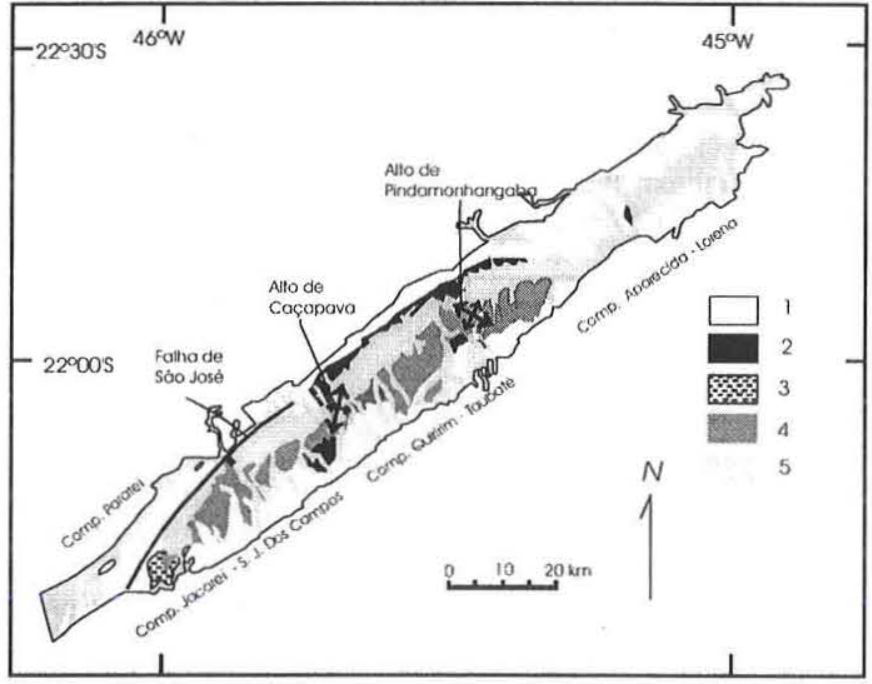

Figura 2 - Mapa esquemático geológico e estrutural da Bacia de Taubaté. 1) Formação Resende; 2) Formação Tremembé; 3) Formação São Paulo; 4) Formação Pindamonhangaba; 5) sedimentos quaternários (adaptado de Riccomini (1989) e Fernandes (1993)).

bem desenvolvido na porção central da Bacia de Taubaté (Fig. 2).

Por fim, ocorrem os sedimentos aluviais e coluviais quaternários, posicionados ao longo das drenagens principais dos rios da região. Tanto os sedimentos da Formação Pindamonhangaba, como 
os depósitos quaternários, apesar da grande extensão areal, apresentam pouca espessura, inferiores a $30 \mathrm{~m}$.

HIDROGEOLOGIA Com aproximadamente 700 poços catalogados, a Bacia de Taubaté é caracterizada pelo grande potencial de exploração e elevada heterogeneidade de seus aqüíferos (Campos 1993).

As regiões de São José dos Campos e Lorena são consideradas as mais promissoras para exploração de água subterrânea, com vazões que variam de 10 a $200 \mathrm{~m}^{3} / \mathrm{h}$, enquanto a região central da bacia, entre os municípios de Taubaté e Pindamonhangaba, apresenta características menos favoráveis à exploração, com vazões situadas entre 20 e $30 \mathrm{~m}^{3} / \mathrm{h}$ (DAEE 1977, Teissedre \& Mariano 1978).

A maior parte dos aquíferos está sob condições freáticas ou pouco confinadas, com pressão acima da hidrostática somente em áreas limitadas (Frangipani \& Panuti 1965, DAEE 1977). O fluxo de água subterrânea acompanha, grosso modo, as cotas topográficas em direção à drenagem principal, representada pelo Rio Paraíba do Sul.

Os aqüíferos são caracterizados pela interdigitação de arenitos e lamitos, recebendo a denominação de aqüífero multicamada. Localmente, pode-se adotar o aqüífero dividido em vários subaquíferos, segundo o número de camadas arenosas no perfil.

Para toda a bacia, o $\mathrm{pH}$ varia de 4,5 a 8,5 . Os valores de resíduo seco apresentam variação de 20 a $683 \mathrm{mg} / \mathrm{L}$, sendo que a maioria dos dados não ultrapassa $300 \mathrm{mg} / \mathrm{L}$ de teor salino (Fig. 3). As águas são classificadas como bicarbonatadas sódicas e bicarbonatadas cálcicas e, secundariamente, como clorosulfatadas sódio-cálcicas (Szikszay 1980). Observa-se na bacia a presença de anomalias hidroquímicas, com valores pontuais excessivos de fluoreto, sulfato, cloretos e de teor salino (DAEE 1977, Teissedre \& Mariano 1978, Campos 1993).

Vidal \& Chang $(1998,2002)$, ao caracterizarem a variação hidroquímica da água subterrânea na Bacia de Taubaté, definiram quatro tipos hidroquímicos, que possuem relação direta com a concentração salina.

O tipo I refere-se às águas associadas aos sedimentos fluviais da Formação Resende, que se caracterizam pela baixa concentração salina e pH ácido-neutro, sendo classificadas como bicarbonatadas cálcicas e sódicas.

As águas do tipo II ocorrem associadas aos sedimentos fluviais, porém mais distantes das áreas de recarga, exibindo teores elevados de $\mathrm{Ca}^{+2}, \mathrm{Mg}^{+2}, \mathrm{SO}_{4}^{-2}, \mathrm{HCO}_{3}$, e $\mathrm{pH}$ alcalino, sendo classificadas como bicarbonatadas cálcicas e sódicas.

O tipo III compreende águas com forte influência dos sedimentos lacustres, classificadas como bicarbonatadas sódicas, $\mathrm{pH}$ alcalino e concentração salina superior a $250 \mathrm{mg} / \mathrm{L}$.

O tipo IV corresponde às águas amostradas exclusivamente em sedimentos lacustres, classificadas como bicarbonatadas sódicas, apresentando as maiores salinidades, $\mathrm{pH}$ alcalino e baixas concentrações de $\mathrm{Ca}^{+2}$ e $\mathrm{Mg}^{+2}$.

SALINIDADE DA ÁGUA SUBTERRÂNEA A análise da salinidade da água subterrânea baseou-se na variável Sólidos Totais Dissolvidos (STD), que é determinada pela somatória dos íons dissolvidos na água, sendo correlacionável com variáveis como condutividade elétrica e resíduo seco.

As análises físico-químicas utilizadas para a determinação de STD somam 141 amostras, sendo 77 análises selecionadas da publicação do DAEE (1977) e 64 coletadas para este trabalho.

A maioria dos poços amostrados está posicionada nas regiões sudoeste, onde estão presentes os municípios de São José dos Campos e Jacareí, e nordeste, na área referente aos municípios de Guaratinguetá e Lorena. A menor ocorrência se dá na porção central, entre as cidades de Taubaté, Pindamonhangaba e Tremembé.

Os valores de STD mostram distribuição assimétrica, com média de $170 \mathrm{mg} / \mathrm{L}$, valor mínimo de $19 \mathrm{mg} / \mathrm{L}$ e máximo de $1.272 \mathrm{mg} / \mathrm{L}$. A assimetria positiva para esta variável aponta a maior ocorrência para águas de baixa salinidade, com mediana de $134 \mathrm{mg} / \mathrm{L}$ e $75 \%$

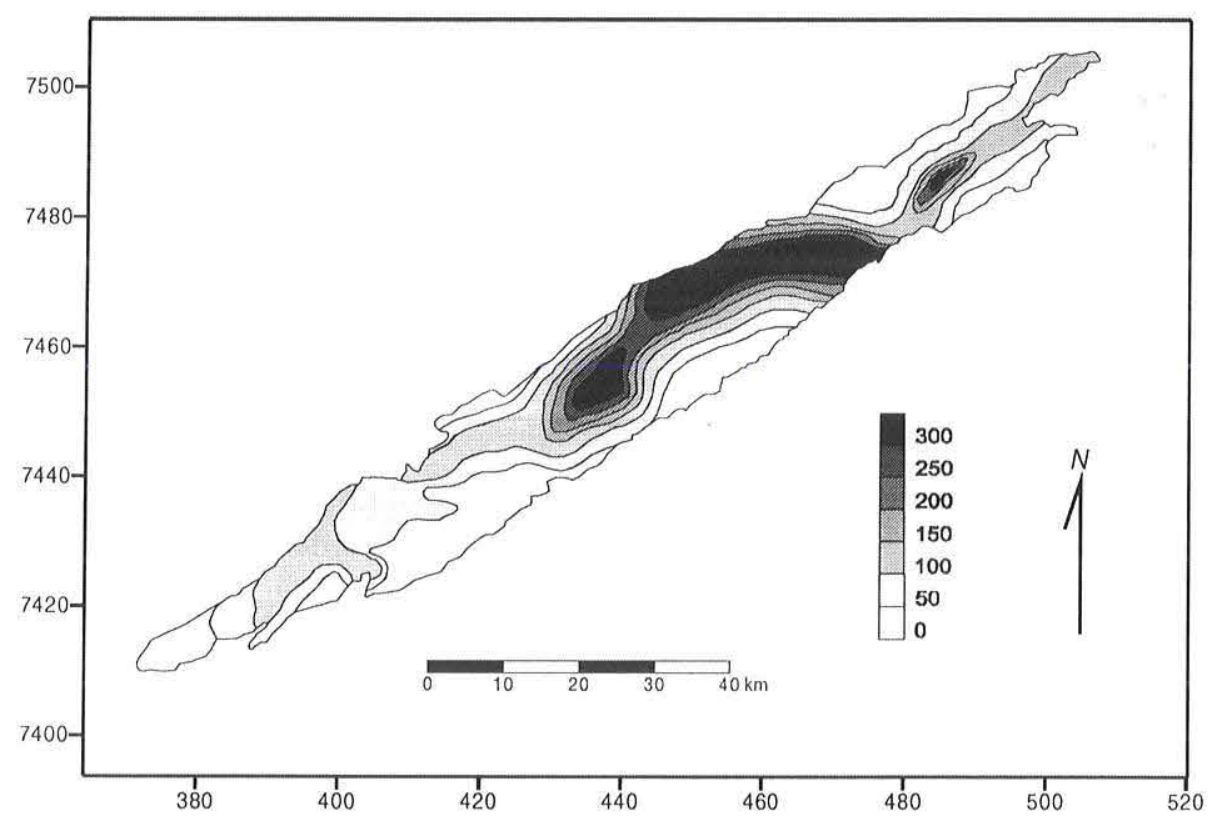

Figura 3 - Mapa de resíduo seco (DAEE 1977). As concentrações estão representadas em mg/L. 
dos dados com valores inferiores a $214 \mathrm{mg} / \mathrm{L}$.

O variograma omnidirecional, realizado para todos os dados da bacia, mostra a não estacionaridade, com comportamento de deriva para o distanciamento dos pares de pontos de $18 \mathrm{~km}$ até $54 \mathrm{~km}$, distância próxima à metade do comprimento da bacia (Fig. 4). Ao analisar os pares de pontos utilizados no variograma, nota-se que a não estacionaridade é causada pelo contínuo aumento da salinidade em direção ao centro da bacia.

Como o variograma de STD apontou a não estacionaridade, o mapa de salinidade foi traçado utilizando-se a deriva quadrática, que adota uma equação polinomial para a estimativa (Fig. 5).

Como esperado, o mapa apresenta grande similaridade com a distribuição de resíduo seco (Fig. 3), com os maiores valores posicionados na região central da bacia. Observa-se que nas bordas e nos extremos norte e sul, regiões em que predominam os sedimentos arenosos da Formação Resende, ocorrem as menores concentrações salinas, enquanto na região central, onde predominam os sedimentos lacustres, há a presença das águas de maior salinidade.

A interação entre os pontos situados nos sedimentos fluviais com os inseridos nos sedimentos lacustres foi responsável pela não estacionaridade no variograma.

De acordo com Isaaks \& Srivastava (1989), a não estacionaridade não implica no abandono da krigagem ordinária e, sim, em uma justificativa para a subdivisão dos dados em populações distintas, onde a estacionaridade é mais apropriada.

A necessidade de uma análise isolada entre as áreas onde predominam os sedimentos fluviais e a área central, de predomínio dos sedimentos lacustres, foi salientada por DAEE (1977), Teissedre \& Mariano (1978).

A interpolação do conjunto total de dados de STD para uma bacia que apresenta compartimentação estrutural e zonalidades litológicas marcantes, ocasiona maior erro de estimativa ao incorporar regiões com características hidrogeológicas distintas. Desta forma, foi utilizada neste trabalho a subdivisão dos dados de acordo com a compartimentação estrutural da bacia, resultado da tectônica do tipo rifte que influenciou na disposição faciológica dos sedimentos do Grupo Taubaté.

A divisão poderia ser realizada com relação ao predomínio litológico, sedimentos lacustres versus fluviais, mas este procedimento foi descartado por não haver um controle preciso dos limites litológicos em subsuperfície.

Deste modo, a divisão dos dados, baseada na compartimentação estrutural definida por Fernandes (1993) e Fernandes \& Chang (2003), considerou as principais sub-bacias, Jacareí-São José dos Campos, Quiririm-Taubaté e Aparecida-Lorena. Devido à ausência de dados, foi descartada a análise do Compartimento Parateí.

Compartimento Jacareí - São José dos Campos Este compartimento tem profundidade máxima de $300 \mathrm{~m}$ e é composto predominantemente por sedimentos arenosos da Formação Resende. Do total de 59 poços selecionados, a salinidade média encontrada é de $85 \mathrm{mg} / \mathrm{L}$, com mediana de $62 \mathrm{mg} / \mathrm{L}$, valor mínimo de $19 \mathrm{mg} / \mathrm{L}$, máximo de $214 \mathrm{mg} / \mathrm{L}$ e desvio padrão de 54,5 .

O variograma experimental executado para este compartimento apresenta baixo valor de alcance, que não ultrapassa $500 \mathrm{~m}$, e componente pepítico na origem, indicando a baixa continuidade espacial. Outra característica é a ciclicidade no comportamento de STD, observado no variograma através do efeito buraco (Fig. 6A).

Tanto a baixa continuidade como o componente pepítico na origem, refletem a característica aleatória da concentração de STD

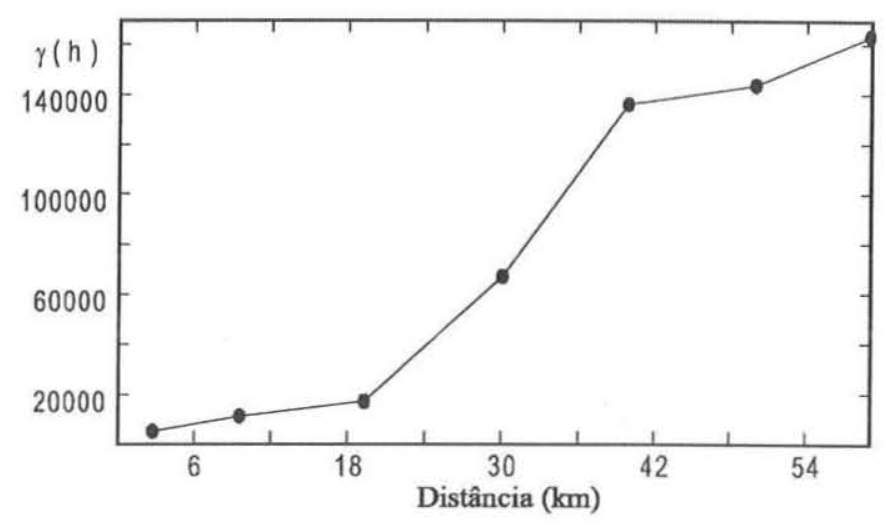

Figura 4 - Variograma experimental omnidirecional de STD, realizado com todos os dados da bacia.

neste compartimento, sem a presença de uma tendência regional significativa. A homogeneidade litológica faz com que a salinidade das águas não apresente direções preferenciais de aumento da concentração salina, sendo a variação na salinidade provocada por outros fatores, como condutividade hidráulica, tempo de residência da água de chuva infiltrada, elevação dos poços, número e localizações dos intervalos de filtros, distribuição heterogênea de teor de matriz e de sedimentos argilosos, além das anomalias pontuais distribuídas nas bordas do compartimento.

O efeito buraco reflete o comportamento cíclico da variável (Isaaks \& Srivastava 1989). Esta ciclicidade provavelmente é conseqüência da influência da topografia na distribuição da salinidade do aquífero.

O mapa de salinidade para este compartimento foi krigado utilizando um modelo esférico com alcance de $500 \mathrm{~m}$, patamar de 2000 e componente pepítico de 500 (Fig. 6A). Este mapa aponta a região central como a de mais baixa salinidade que, aliada à elevada altitude, faz dessa região uma área de predominante recarga. As regiões de maior salinidade estão posiciơnadas junto à margem do Rio Paraíba do Sul, descarga principal do aquíífero.

Compartimento Quiririm-Taubaté Este compartimento tem profundidade máxima de $600 \mathrm{~m}$, com predomínio de arenitos e conglomerados nas bordas e argilitos no centro. Os 25 poços selecionados, com salinidade média de $267 \mathrm{mg} / \mathrm{L}$ e mediana de $240 \mathrm{mg} / \mathrm{L}$, apresentam como principal característica a grande variação nas concentrações de STD, com valor mínimo de $33 \mathrm{mg} / \mathrm{L}$, máximo de $842 \mathrm{mg} / \mathrm{L}$ e desvio padrão de 208.

O variograma experimental realizado no Compartimento QuiririmTaubaté mostrou marcante deriva linear. Até o distanciamento de $3.000 \mathrm{~m}$, as relações entre os pares de pontos correspondem aos poços com salinidades semelhantes. A partir deste comprimento começa haver a interação entre os poços situados nas bordas com os do centro da bacia, o que ocasiona o aumento na variância.

O comportamento de deriva bem marcado demonstra o aumento contínuo da salinidade das bordas da bacia em direção ao centro, onde o pacote sedimentar é composto por depósitos lacustres (Fig. 6B). O mapa produzido, utilizando uma única equação polinomial, mostra o marcante aumento da salinidade em direção ao interior da sub-bacia.

As águas do centro deste compartimento são as mais salinas da bacia, com valores superiores a $700 \mathrm{mg} / \mathrm{L}$, enquanto nas bordas as 


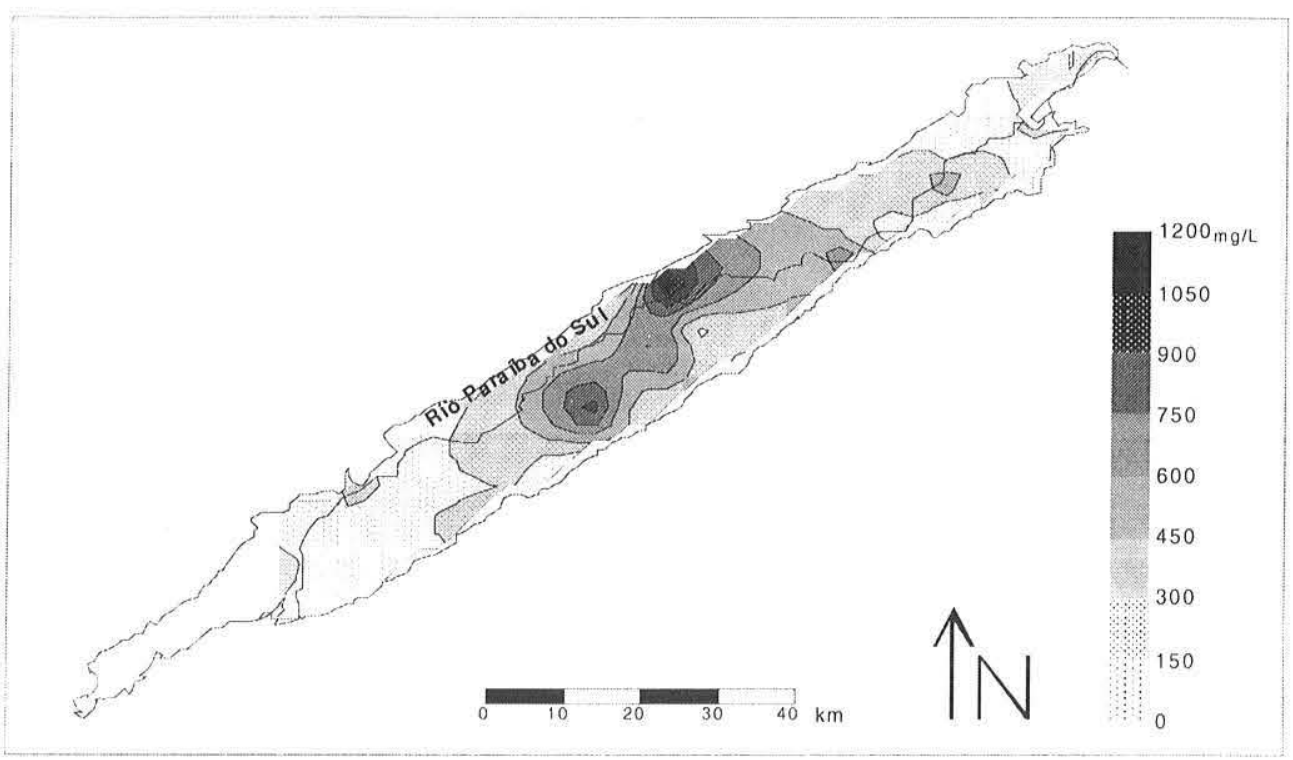

Figura 5 - Mapa de STD, utilizando todos os dados da bacia.

salinidades encontradas são inferiores a $250 \mathrm{mg} / \mathrm{L}$. Nota-se que esta variação ocorre para distâncias inferiores a $10 \mathrm{~km}$ em algumas regiões do compartimento.

Compartimento Aparecida-Lorena É o maior da bacia e tem profundidade máxima de $800 \mathrm{~m}$. Apresenta a oeste o predomínio de sedimentos lacustres, enquanto a leste predominam os sedimentos de origem fluvial. Do total de 41 poços, a salinidade média encontrada é de $235 \mathrm{mg} / \mathrm{L}$, mediana de $202 \mathrm{mg} / \mathrm{L}$, com valor mínimo de $51 \mathrm{mg} / \mathrm{L}$ e máximo de $1.221 \mathrm{mg} / \mathrm{L}$. O desvio padrão de 207 é muito influenciado por um único poço presente no extremo oeste e que é responsável pelo valor máximo de STD encontrado no compartimento.

O variograma experimental referente a este compartimento apresenta maior continuidade, com alcance de $3000 \mathrm{~m}$, se comparado com o Compartimento Jacareí - São José dos Campos, que apresentou valor de alcance de $500 \mathrm{~m}$ (Fig. 6C).

Ao analisar os pares de pontos utilizados no variograma experimental, observa-se que a sua forma é produto da interação entre os valores situados na região de Lorena, Guaratinguetá e Aparecida do Norte, região de maior densidade de poços deste compartimento.

A continuidade de até $3.000 \mathrm{~m}$ ocorre devido à presença de unidades lacustres no centro da região nordeste, ocasionando o aumento da salinidade em direção aos sedimentos finos. A ocorrência dos sedimentos lacustres é coincidente com as menores altitudes junto à margem do Rio Paraíba do Sul. O efeito buraco também é identificado neste variograma, e se deve à influência da topografia nos aqǘferos livres.

O mapa de salinidade, produzido por meio de modelo gaussiano de alcance de $3.000 \mathrm{~m}$ e patamar de 2.500 , ilustra grandes áreas de baixa salinidade a nordeste no compartimento, onde predominam sedimentos fluviais. No entanto, distinguem-se do Compartimento São José dos Campos por apresentarem regiões junto ao Rio Paraíba do Sul com altas salinidades (Fig. 6C).

$\mathrm{O}$ extremo oeste do compartimento apresenta problemas de interpolação das curvas de isovalores devido à pouca quantidade de dados. Além disso, ao analisar o mapa geológico, pode-se constatar a presença de grande unidade lacustre da Formação Tremembé que se prolonga desde o Compartimento QuiririmTaubaté até próximo ao centro do Compartimento AparecidaLorena. Isto faz com que as águas desta região apresentem elevada concentração salina, diferente da encontrada para a maioria dos poços da região de Lorena e Guaratinguetá, onde predominam os sedimentos fluviais.

MAPA GERAL A confecção do mapa de STD para toda a bacia, preservando o modelo variográfico de cada compartimento, foi realizado com a utilização de uma malha única cobrindo toda a extensão da bacia, sendo os valores krigados para as dimensões do novo grid para os três compartimentos. Nas células posicionadas nos limites onde ocorre a sobreposição entre os valores krigados, foi calculada a média aritmética. Com isso, foi confecionado um mapa de salinidade para toda a bacia, enfatizando sua distribuição nos compartimentos estruturais (Fig. 7).

O mapa de STD composto a partir da integração dos três compartimentos apontou semelhanças na distribuição das regiões de maior e menor salinidade, quando comparado com os mapas de resíduo seco e de STD utilizando o conjunto total de dados da bacia. Entretanto, a forma das curvas de isovalores e a área de ocorrência de cada salinidade variam significativamente.

Outro aspecto a ser considerado, é a significativa diferença da salinidade entre as sub-bacias definidas no mapa por compartimentos: as regiões de Lorena e São José dos Campos, classificadas como semelhantes do ponto de vista hidrogelógico por DAEE (1977) e Teissedre \& Mariano (1978) apresentam diferenças quanto ao aspecto hidroquímico.

Para avaliar a eficiência da estimativa por compartimentos em relação à da bacia, como um todo, sem compartimentação, confrontou-se o valor real medido da amostra, com o estimado para a célula do grid onde ela está inserida.

A diferença entre os valores estimado e real, denominado resíduo, está apresentada na forma de histograma para os dois procedimentos de estimativa (Fig. 8). Os resultados apresentam disper- 

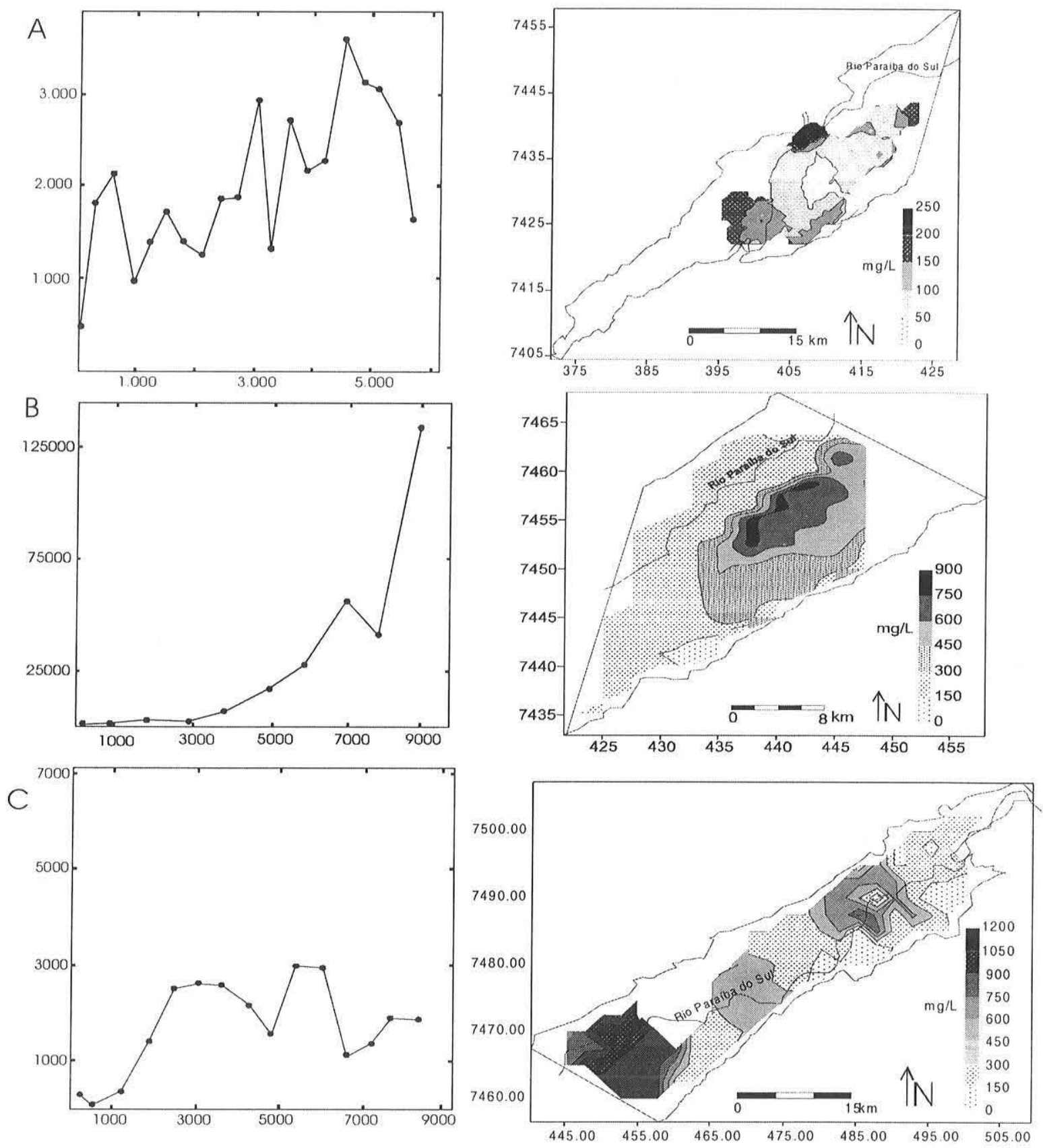

Figura 6 - Variogramas experimentais omnidirecionais e mapas de STD referentes a cada compartimento da Bacia de Taubaté. (A) Compartimento Jacarei-São José dos Campos; (B) Compartimento Quiririm-Taubaté; (C) Compartimento Aparecida-Lorena.

são dos dados diferenciados para os dois casos: na estimativa para toda a bacia o desvio padrão é de 58,6 , enquanto na estimativa por compartimentos o desvio padrão é de 32,8 .

Esta menor dispersão dos dados indica que um maior número de pontos apresentou valores estimados mais próximos do valor real.

A maior dispersão dos dados na estimativa para toda a bacia confirma a marcante heterogeneidade hidrogeológica constatada por vários autores ao subdividirem as bordas da bacia e sua região central (Frangipani \& Panuti 1965, DAEE 1977, Teissedre \& Mariano 1978).

Quando a análise de dispersão dos resíduos é avaliada por compartimento, pode-se constatar que a utilização dos altos estrutu- rais, definidos por Fernandes (1993) para a subdivisão da bacia, é muito eficiente para a estimativa da salinidade dos Compartimentos Jacareí-São José dos Campos e Quiririm-Taubaté, mas apresenta problemas para o Compartimento Aparecida-Lorena. O desvio padrão dos resíduos para o Compartimento Jacareí-São José dos Campos apresentou valor de 29,7, o Compartimento QuiririmTaubaté de 13,7 e o Compartimento Aparecida-Lorena de 44,1.

O Compartimento Aparecida-Lorena é o maior da bacia e engloba regiões com predomínio de sedimentos lacustres na porção oeste e de sedimentos fluviais na porção leste. A união destas duas regiões em um mesmo compartimento acarreta maior variabilidade dos dados e problemas na definição de um modelo de 


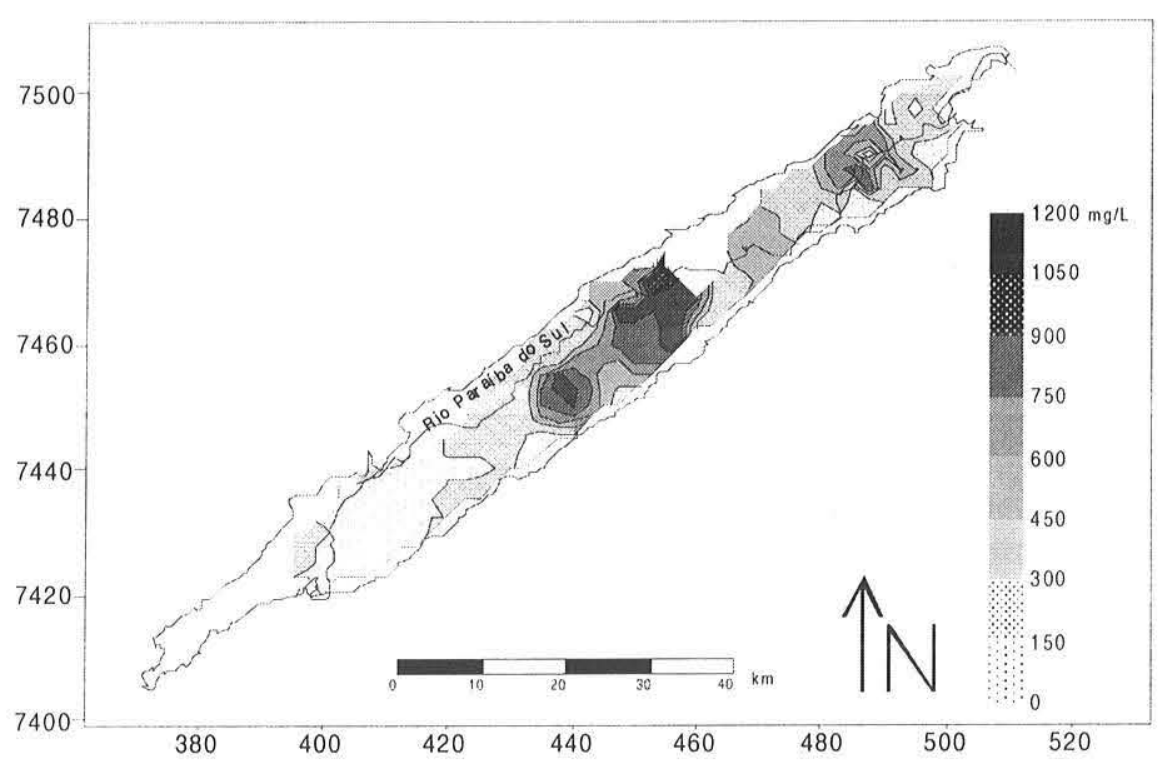

Figura 7 - Mapa de STD realizado com a união dos mapas gerados por compartimentos estruturais.
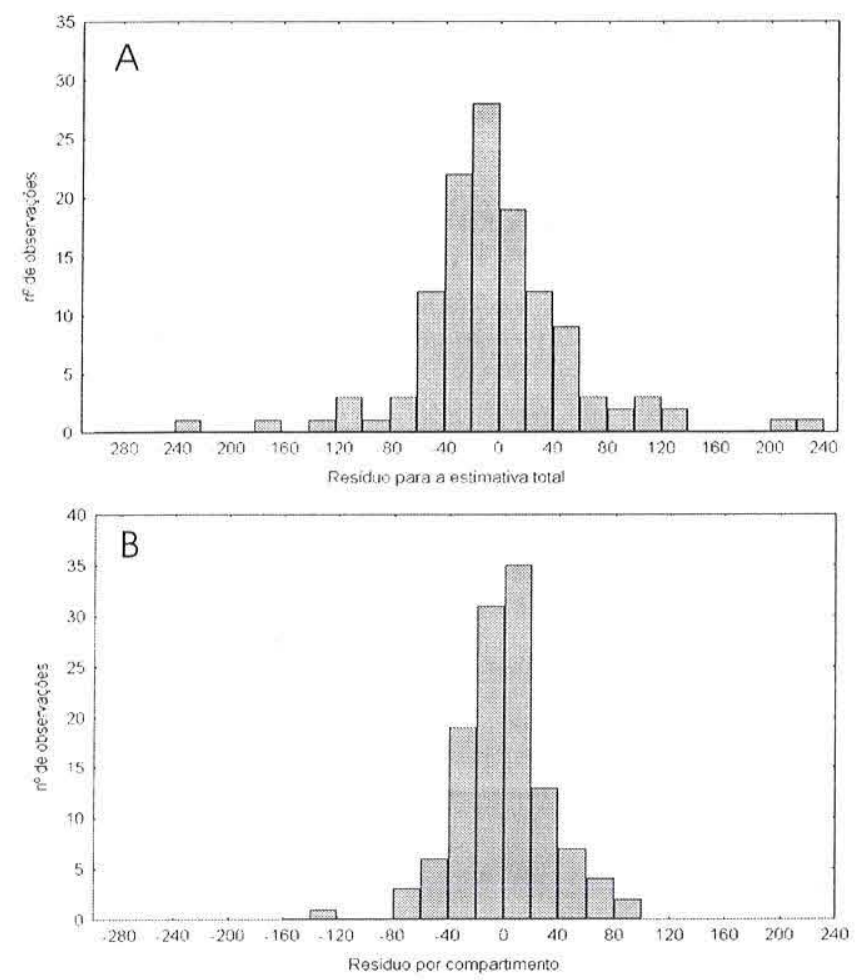

Figura 8 - Histogramas de resíduo para estimativa total da bacia $(A)$ e por compartimentos $(B)$.

interpolação.

Subdivisões para a região do Compartimento Aparecida-Lorena foram adotadas por outros autores. DAEE (1977) subdivide a região em três sub-bacias, separadas pelos altos estruturais de Aparecida e Cachoeira Paulista. Hasui \& Poçano (1978) subdividem o compartimento apenas pelo Alto de Aparecida e, por fim, Marques (1990) faz a subdivisão do compartimento pelo Alto de
Capela Santa Luzia, localizado próximo ao município de Aparecida do Norte. Os resultados obtidos no mapeamento da salinidade deste compartimento comprovam a necessidade da subdivisão. Neste caso, a escolha mais apropriada seria a divisão pelo Alto de Aparecida, conforme os autores supracitados.

Os maiores desvios do resíduo, nos dois histogramas, devemse, em grande parte, a pontos anômalos situados próximos à borda da bacia. A composição química destas águas pode sofrer influência de fluxo ascendente relacionado ao embasamento cristalino e às principais falhas da bacia.

Vale ressaltar que este trabalho não considerou a influência da profundidade dos poços sobre a salinidade, pois análises preliminares mostraram que a salinidade é pouco influenciada pela profundidade, onde o coeficiente de correlação linear é de 0,21 entre estas variáveis (Fig. 9). Desta forma reforça-se o controle da rocha na variação da salinidade.

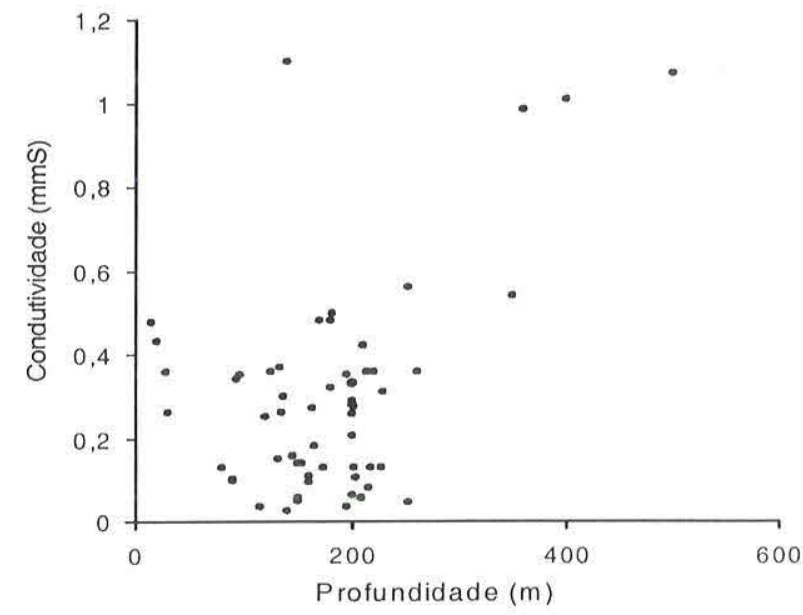

Figura 9 - Correlação entre condutividade elétrica versus profundidade com coeficiente de correlação linear $R^{2}=0,21$. 
Mudanças na configuração dos mapas apresentados e a análise da salinidade em relação à profundidade só serão possíveis com a incorporação de novos dados e a definição da distribuição dos tipos litológicos em subsuperfície.

CONCLUSÃO A análise da distribuição da salinidade no Sistema Aqüífero Taubaté mostrou a grande variabilidade da composição química da água subterrânea, com valores que variam de 20 a $1.200 \mathrm{mg} / \mathrm{L}$.

Os teores salinos das águas coletadas, quando analisado em mapa, apresentam clara zonalidade hidroquímica, condicionada pela compartimentação estrutural e distribuição dos tipos litológicos dos sedimentos do Grupo Taubaté.

A confecção de um mapa único de salinidade que buscasse incorporar a heterogeneidade presente na bacia foi realizada através da junção dos mapas krigados para cada compartimento. Este procedimento acarretou menores erros de estimativa, se comparado com o procedimento de interpolação para a bacia como um todo, demonstrando a importância do conhecimento geológicoestrutural em estudo hidrogeológicos e hidroquímicos.

Os resultados obtidos apontaram as regiões dos Compartimentos Jacareí-São José dos Campos e Quiririm-Taubaté com zonalidades hidroquímicas bem definidas. Porém, o Compartimento AparecidaLorena apresentou maiores erros de estimativa, indicando a necessidade da subdivisão deste compartimento para melhor caracterização da salinidade.

Agradecimentos À Fundação de Amparo a Pesquisa do Estado de São Paulo - FAPESP, pelo auxílio a pesquisa (processo nº6/ 2877-0). Aos revisores da RBG pelas sugestões ao manuscrito.

\section{Referências}

Campos H.C.N.S. 1993. Caracterização e cartografia das províncias hidrogeoquímicas do Estado de São Paulo. Inst. de Geociências, Universidade de São Paulo, São Paulo, Tese de Doutoramento, 117p.

DAEE - Departamento de Águas e Energia Elétrica. 1977. Estudo de águas subterrâneas da regiāo administrativa 3 ( São José dos Campos e Faixa Litorânea), SP. São Paulo, 175p.

Fernandes F.L. 1993. Arcabouço estrutural e evolução da Bacia de Taubaté - SP. Escola de Minas, Universidade Federal de Ouro Preto, Ouro Preto, Tese de Mestrado, 147p.

Fernandes F.L. \& Chang H.K. 2003. Modelagem gravimétrica da Bacia de Taubaté - Vale do Rio Paraíba do Sul, leste do Estado de São Paulo. Revi. Bras. Geof., (no prelo).

FRANGIPANI, A. e PANNUTI, E. L., 1965. Estudos Hidrológicos na Bacia de Taubaté, entre Jacareí e Quiririm. Bol. do $I G G, \mathrm{n}^{\circ} 42$, São Paulo, 126p.

Hasui Y. \& Ponçano W.L. 1978. Organização estrutural e evolução da Bacia de Taubaté. In: SBG, Cong. Bras. Geol., 30, Recife, v. 1, p. 368381 .

Isaaks E. \& Srivastava R. 1989. An Introduction to Applied Geostatistics. Oxford Un. Press. New York.

Marques A. 1990. Evolução tectono-sedimentar e perspectivas exploratórias da Bacia de Taubaté, SP, Brasil. Bol. Geoc. Petrobrás, 4(3):253-262.

Riccomini C. 1989. O Rift Continental do Sudeste do Brasil. Inst. de Geociências, Universidade de São Paulo, São Paulo, Tese de Doutoramento, 256p.

Szikszay M.1980. Avaliação da qualidade das águas subterrâneas: uma metodologia aplicada nas regiões do Vale do Paraíba e Ribeirão Preto - Estado de São Paulo. Revista Brasileira de Águas Subterrâneas, 2(1): 26-32.

Teiseidre J.M. \& Mariano I.B. 1978. Possibilidades hidrológicas da Bacia de Taubaté. SBG. 6:3003-3011.

Vidal A.C. \& Chang H.K. 1998. Caracterização hidroquímica do Sistema aquífero Taubaté. XL Congresso Brasileiro de Geologia. Belo Horizonte, Anais. Belo Horizonte, SBG.

Vidal A.C. \& Chang H.K. 2002. Caracterização hidroquímica dos aquííferos da Bacia de Taubaté. Rev. Bras. Geoc., 32(2):267-276.

Manuscrito A-1412

Recebido em 06 de fevereiro de 2003

Revisão dos autores em 26 de janeiro de 2004

Revisão aceita em 30 de janeiro de 2004 